\title{
The Opper Project: Collaborating with Educators to Promote the Use of Editorial Cartoons in the Social Studies Classroom
}

CURATORS, ARCHIVISTS, AND LIBRARIANS who work in special collections, including those affiliated with institutions of higher learning, are increasingly debating the advantages and importance of serving wider user populations, with particular emphasis on $\mathrm{K}-12$ educators and students. Likewise, $\mathrm{K}-12$ teachers have been increasingly encouraged - even mandated - to make use in their pedagogy of the kinds of primary documents that are located in special collections and archives. The challenge for special collections professionals is to know what might be useful in the $\mathrm{K}-12$ classroom and how to make it available in a way that protects the physical objects. The challenge for teachers is to locate relevant materials at institutions with often very limited hours and access policies. Collaboration between the two is the obvious solution, but that can be a daunting undertaking for two groups who, more often than not, work in separate worlds. Ideal collaborations result in projects that are not overly labor intensive for any of the partners and produce valuable educational materials that reach a wide audience. This paper presents a case study of a collaboration, between The Ohio State University Cartoon Library and Museum and university and secondary school educators, that promotes the use of editorial cartoons in U.S. history classrooms. The project was named the Opper Project after Ohio native Frederick Burr Opper (1857-1937), one of the first great American-born editorial cartoonists.

\section{Literature Review}

Writing in the Canadian journal Archivaria in 1986, teacher and education professor Ken Osborne issued a call to action to archivists to embrace their role as educators by supporting the efforts of teachers to make use of archival materials in the classroom. ${ }^{1}$ Shirking this responsibility, he argued, would deprive schools of invaluable teaching resources, society of the information contained in the documents that could advance human knowledge, and the archives themselves of "the possibility

1. Ken Osborne, "Archives in the Classroom," Archivaria 23 (Winter 1986-1987): 16-40. 
of building and benefitting from the support of a knowledgeable and sympathetic public."2 Osborne traced the developments in social studies pedagogy culminating in the "new history" movement of the 1960s and 1970s that discouraged the teaching of history as a set of facts to be memorized and instead focused on studentcentered methods that encourage the development of research and analytical skills and an understanding of historiography. He concluded that the use of primary documents in teaching had become increasingly popular, even necessary, but that a lack of "resources and mechanisms" for gaining access to such materials was standing in the way. ${ }^{3}$

That same year, the UNESCO report Archives and Education: A RAMP Study with Guidelines also called for a more active attempt on the part of archives to contribute to primary and secondary education. ${ }^{4}$ The report recounts such efforts in the United States and various European countries, giving examples and offering suggestions and guidelines for future projects and programs. One of the obstacles identified was a lack of archival staff resources: "It will be impossible to charge the archivist with a whole complex of new, time-consuming tasks in the educational domain without impairing work in the fields of appraisal and preservation, of arrangement and description, which must always remain the archivist's primary responsibility." Also citing the archivist's lack of practical teaching experience, the report stresses the importance of collaboration with educators to overcome these challenges. ${ }^{6}$

A decade later, Sharon Anne Cook reported that the response to this call had been less than satisfactory and there was little evidence of the "creative pedagogical materials and strategies" that should have been an important part of increased archival public programming. ${ }^{7}$ She found that those programs that had been attempted were localized and dependent on individual efforts. "The prime reason so few projects have been initiated is undoubtedly financial restraint," Cook writes, adding that "archivists—old and new—feel that they lack the requisite skills to mount effective public and educational programmes." Given these challenges, Cook also emphasized the importance of partnerships between archivists and teachers to produce useful curricular materials.

More recently, Julia Hendry, writing in the American Archivist a decade after Cook, once again takes up the subject in her article "Primary Sources in K-12 Education:

2. Ibid.,16-17.

3. Ibid., 27.

4. Eckhart G. Franz, Archives and Education: A RAMP study with Guidelines (Paris: Unesco, 1986).

5. Ibid., 28 .

6. Ibid., 29.

7. Sharon Anne Cook, "Connecting Archives and the Classroom," Archivaria 44 (fall 1997): 102-17.

8. Ibid., 104-05. 
Opportunities for Archives." Hendry notes that, while a relatively small number of articles in the archival literature discuss serving $\mathrm{K}-12$ users, recent education literature contains "dozens of books, hundreds of articles, and uncounted Web sites devoted to the topic of incorporating primary sources into classroom instruction." She provides an excellent summary of the factors that make primary sources even more necessary to teachers now than they were when Osborne and Franz were writing, including the development of "pedagogical theory in support of inquirybased learning, the use of DBQs (document-based questions) on standardized tests, and a political climate that has raised the stakes for these standardized tests." ${ }^{10}$ However, she concludes that, in spite of considerable advances, teachers still have difficulty locating, acquiring, and making use of appropriate primary documents, thus offering archivists a unique and beneficial outreach opportunity. Specifically, she recommends that archives wishing to reach a precollegiate audience create online digital collections aimed at $\mathrm{K}-12$ teachers and students, with special attention paid to their specific needs. ${ }^{11}$

Anne J. Gilland-Swetland and Matthew Lyons both discuss the opportunities and challenges of using digital technology to provide $\mathrm{K}-12$ users with access to primary sources. Gilland-Swetland surveyed Southern California teachers to identify the characteristics that would make digitized documents useful in the classroom. Respondents mentioned that items should be downloadable, legally reproducible, visually appealing, and directly relatable to academic content standards. In addition, they prefer items for which thorough descriptions and links to related materials are provided. She also reported some of the barriers to use, including a "lack of knowledge of how to work with primary sources" and a "lack of time, tools, and textual tolerance for locating, selecting, and compiling curricular materials." She concludes that the specific needs of teachers must be taken into account when selecting items for digitization and when designing effective delivery systems. ${ }^{12}$ Lyons agrees that there are many benefits to digital access, but he also cites some of the drawbacks, including design and maintenance problems on some sites, the inability to experience the physical object itself and the institution that houses it, and the lack of computer equipment and online access at schools with fewer financial resources. ${ }^{13}$ However, he concludes that, "at their best, such sites provide tools that help history come alive as a complex, subjective process that all of us are part of and all of us can interpret." ${ }^{14}$

9. Julia Hendry, "Primary Sources in K-12 Education: Opportunities for Archives," The American Archivist 70 (spring/summer 2007): 114-29.

10. Ibid., 124.

11. Ibid., 126 .

12. Anne J. Gilliland-Swetland, "An Exploration of K-12 User Needs for Digital Primary Source Materials," The American Archivist 61 (spring 1998), 136-57.

13. Matthew Lyons, "K-12 Instruction and Digital Access to Archival Materials," Journal of Archival Organization 1.1 (2002), 19-34.

14. Ibid., 31. 
The clarion call for greater collaboration between $\mathrm{K}-12$ educators and the caretakers of primary documents is by no means restricted to archives. Cathy Henderson's article in Rare Books and Manuscripts Librarianship entitled "Negotiating New Borders for Special Collections" discusses the push for increased outreach to "K-12 and other sought after audiences," pointing out that, while some institutions are embracing such educational initiatives, others are finding them imposed by university administrations or participation in communitywide partnerships. ${ }^{15}$ Writing in RBM in 2005, Steven Escar Smith acknowledges that "outreach and education have simply not been mainstays of our work, especially when compared to our colleagues in public and school libraries or even, for that matter, to the general academic library." ${ }^{16} \mathrm{He}$ argues for the importance of bringing special collections to the classroom and the classroom to special collections. Not making this a priority, in spite of the challenges and expenses, "will ultimately cost more because it erodes our most important capital—an enlightened, engaged, and supportive public." ${ }^{17}$

Michelle Visser agrees that outreach to the $\mathrm{K}-12$ audiences "can be an influential bridge to the community that helps build both lifelong learners and library supporters." ${ }^{18}$ Her article, "Special Collections at ARL Libraries and K-12 Outreach: Current Trends" presents the results of a survey of ARL (American Research Libraries) special collections librarians about their K-12 outreach attitudes, policies, and practices. The survey focused on hosting $\mathrm{K}-12$ students either as researchers or in organized class visits and did not specifically discuss collaborations for curriculum development or digital collections. It is, however, interesting to note that she found a positive attitude toward serving $\mathrm{K}-12$ users among respondents who reported hosting class visits ( $76 \%$ of total respondents), with 52 percent of them stating that they actively reached out to $\mathrm{K}-12$ students and teachers. Although several respondents pointed out that this type of public programming is not central to their missions, others reported that they would like to do more but are prevented from it by lack of staff, time, or adequate facilities.

Given the interest in collaborations between special collections and $\mathrm{K}-12$ educators to promote the use of primary documents in classrooms, it is surprising that there are not more case studies of successful projects described and evaluated in library and special collections literature. Certainly, many institutions have attempted this type of project, ranging from national, large-scale efforts such as the Library of Congress's American Memory Project and the National Archives and Records

15. Cathy Henderson, "Negotiating New Borders for Special Collections," Rare Books and Manuscripts Librarianship 14.1 (fall 1999): 9-17.

16. Steven Escar Smith, "From 'Treasure Room' to 'School Room': Special Collections and Educa-

tion," RBM: A Journal of Rare Books, Manuscripts, and Cultural Heritage 7.1 (spring 2006): 31-39.

17. Ibid., 39.

18. Michelle Visser, "Special Collections at ARL Libraries and K-12 Outreach: Current Trends," The Journal of Academic Librarianship 32.3 (May 2006): 313-19. 
Administration's Digital Classroom ${ }^{19}$ to local, small-scale efforts by individual institutions. However, if significant progress has been made, the programs are not often written about in relevant journals. Few examples could be found to serve as models.

Sharon Anne Cook documented a collaborative project between an archivist, an education consultant, and a teacher. The result was a traditional (nondigital) teaching kit that included a variety of primary documents from the Canadian National Archives accompanied by curricular materials. Although no formal assessment was undertaken, Cook reported that the kit was well received by teachers. She concluded that partnerships that combine the expertise of both archivists and teachers are necessary for effective programming of this type. ${ }^{20}$ Similarly, Anne J. GillilandSwetland et. al. described a collaboration between UCLA Archival Science and Educational Psychology faculty, an archivist, and two elementary school teachers to develop a special classroom unit using documents from the UCLA History of Medicine Collection. Unlike Cook's project, the curriculum was not intended to be widely distributed and was regionally specific to Southern California. However, the project proved that "archivist-teacher partnerships can be extremely effective and rewarding for all participants, even with elementary school students and curricula outside the social sciences" and stressed the importance of teachers' input in each phase of the process. ${ }^{21}$ Yolanda Theunissen describes the extensive outreach efforts of the Osher Map Library and Smith Center for Cartographic Education at the University of Southern Maine, including digital resources and lesson plans created in collaboration with teachers. Outreach to groups beyond traditional academic researchers is part of their mission in accordance with the wishes of their founding donors. She concludes that smaller-scale, low-cost $\mathrm{K}-12$ programs are possible even without a dedicated outreach staff person. ${ }^{22}$ Finally, Tara Zachary Laver published a case study of a partnership between several Louisiana special collections and educators to produce online lesson plans and resources for integrating primary documents related to the Louisiana Purchase into schools. Laver stresses the importance of appropriately timed teacher involvement and of providing contextual information about the documents and the historical time period for teachers. ${ }^{23}$

19. See Lyons, "K-12 Instruction," for a comparison of the historiographic and pedagogical approaches of these two large-scale projects.

20. Cook, "Connecting Archives and the Classroom," 109-15.

21. Anna J. Gilliland-Swetland, Yasmin B. Kafai, and William E. Landis, "Integrating Primary Sources into the Elementary School Classroom: A Case Study of Teachers' Perspectives," Archivaria 48 (fall 1999): 89-116.

22. Yolanda Theunissen, "Developing and Promoting Outreach Services for Elementary and Middle Schools: Case Study of a Rare Map Library at a Public University," Journal of Map \& Geography Libraries 3.2 (2007): 5-22.

23. Tara Zachary Laver, "Off the Shelf and into the Classroom: Working with K-12 Teachers to Integrate Digitized Collections into Classroom Instruction,” The Southeastern Librarian 50.4 (2003): 32-37. 
Recognizing the interest in greater involvement of special collections in $\mathrm{K}-12$ education and the opportunities to reach teachers provided by the Internet, this paper provides a case study of a collaboration that could be replicated by other special collections. A description of the Opper Project is followed by a discussion of the results of an online evaluation survey. Based on site visits, survey results, and reviews of the site, the Opper Project has produced useful pedagogical materials that are facilitating the use of historical editorial cartoons in precollegiate classrooms. Practical suggestions and a discussion of the future of the project are also provided.

\section{Opper Project Team}

The project development team initially consisted of the Curator and Associate Curator from The Ohio State University Cartoon Library and Museum (formerly the Cartoon Research Library), the Director of the OSU Harvey Goldberg Center for Excellence in Teaching, and the Director of the Goldberg Center's History Teaching Institute.

The Cartoon Library and Museum (CLM) is the largest academic collection of cartoon and comics materials in the world. It is one of ten special collections at The Ohio State University and is a library, an archive, and an art collection all in one. Its mission is to develop a comprehensive research collection documenting American cartoon art, to organize the materials, and to provide access to them. Founded in 1977 with the gift of cartoonist Milton Caniff's papers and art, the collection has grown to include more than 36,000 books, 51,000 serial titles, 3,000 linear feet of manuscript materials, 450,000 original works of art, and 2.5 million newspaper clippings and pages. Outreach to the nonacademic community is an important part of its mission, particularly given that the CLM is part of a land-grant university.

The Goldberg Center for Excellence in Teaching (GCET) is an initiative of The Ohio State University Department of History to promote innovative and effective history teaching strategies at the university level and beyond. Its mission is "to provide professional development, focused especially on pursuing the best strategies for teaching with technology; to produce a series of publications designed to provide quality teaching and learning materials; and to engage in significant public outreach, especially aimed at teachers and students of history." ${ }^{24}$ The Goldberg Center runs a wide variety of programs including an Instructional Center that serves as a nexus of teaching resources, speakers' series and lectures, graduate courses, innovative publications that make use of print-on-demand and digital technologies, and a digital archive offering access to more than 10,000 primary records.

24. Harvey Goldberg Center for Excellence in Teaching Website. Available online at http:// goldbergcenter.osu.edu/page.cfm?content=about_main. [Accessed 27 May 2009]. 
The History Teaching Institute (HTI) is the unit within the Goldberg Center that serves $\mathrm{K}-12$ educators in Ohio. It seeks to work with social studies teachers "to develop standards-based social studies curricula, to incorporate primary sources into classroom instruction, and to employ technology to improve teaching and learning in schools across the state." The HTI assists teachers by providing professional development opportunities, such as seminars and summer institutes, and digital resources.

The curators from the Cartoon Library brought to the project team extensive knowledge of editorial cartooning and the resources of the library's collection, along with connections with cartoonists themselves. The Directors of the Goldberg Center and the HTI brought expertise in pedagogical standards, working with $\mathrm{K}-12$ educators, and using digital technologies in history teaching and scholarship, along with connections to teachers and professional educational organizations in Ohio. All participants shared an enthusiasm for editorial cartoons and the benefits of using them as primary sources to teach social studies.

Although not part of the Opper Project planning team, the Association of American Editorial Cartoonists (AAEC) was also a partner on the project. The AAEC is a professional association concerned with promoting the interests of staff, freelance and student editorial cartoonists in the United States. Their "Cartoons for the Classroom" program, presented in association with Newspapers in Education, provides lesson plans for teachers on current events using contemporary editorial cartoons. ${ }^{25}$ The success of their program and the positive response it has received demonstrates teacher demand for classroom activities using cartoons. ${ }^{26}$ The Opper Project was developed to complement the contemporary focus of the AAEC's program with lesson plans based on historical cartoons.

\section{Editorial Cartoons as Primary Documents}

Editorial cartoons document the past in a unique, creative, and entertaining way that is at once visual and textual. They are ideal primary documents for teaching history because they are created at the same time as the events they describe, they express a distinct point of view about those events, and they encourage a familiarity with the personalities, issues, and popular culture of the time period under scrutiny. Deciphering a historical political cartoon requires an active ap-

\footnotetext{
25. NIEonline.com and the Association of American Editorial Cartoonists, "Cartoons for the Classroom," http:// nieonline.com/aaec/cftc.cfm. [Accessed 27 May 2009]

26. "Cartoons for the Classroom" feedback Web site: http:// nieonline.com/aaec/cftc. cfm?cftcfeature $=$ feedback. [Accessed 27 May 2009].
} 
proach and forces students to use critical thinking, analysis, and communication skills. ${ }^{27}$ The ability to interpret editorial cartoons accurately is deemed sufficiently important that many standardized tests include a section requiring students to demonstrate it. In addition, most states' history or social studies academic content standards require proficiency in analyzing primary documents, while some even mentioned cartoons specifically. ${ }^{28}$

Editorial cartoons are available to educators from a variety of sources, including textbooks, Web sites, and printed collections of primary resources and documents, but they are generally presented without supporting pedagogical materials. Also, it can be frustrating to see editorial cartoons published in print or on the Web without the proper metadata or contextual information associated with them. Knowing information about who created the cartoon and where and when it was published is critical to understanding and interpreting it.

The CLM's collection contains millions of cartoons, many of which are editorial or political in nature. Cartoons can be found in the collection in a variety of formats, commenting on almost any historical event, issue, or personality dating back to the eighteenth century. But, in spite of these rich resources and the increased emphasis on using primary documents to teach history, access challenges meant that K-12 educators were a largely untapped user population for the CLM.

When archivists and special collections librarians talk about "hidden collections," they are generally referring to those materials that are unprocessed or semiprocessed. For all intents and purposes, however, even fully processed items in the CLM's collections are "hidden" to educators who do not have the means to plan a trip to visit its reading room, the time to search for appropriate cartoons, or the resources to order digital scans. None of the CLM materials circulate for preservation reasons; and, due to funding realities and copyright restrictions, only a fraction have been digitized and made available online. The public is welcome to visit the CLM; but, again due to limited resources, the reading room is only open during business hours Monday through Friday, precisely when most teachers are in school. Even those who are able to visit may have a difficult time finding what they need in a timely way. While the CLM provides access to its collections through catalogs, databases, and finding aids, such tools were primarily developed to serve the needs of scholars and researchers (who already have experience with special collections)

27. See Brenda Holub and Clifford T. Bennett, "Using Political Cartoons to Teach Junior/Middle School U.S. History," John E. Steinbrink and Donna Bliss, "Using Political Cartoons to Teach Thinking Skills," and Marcia De Fren, "Using Cartoons to Develop Writing and Thinking Skills," in The Social Studies 79.5 (Sept. / Oct. 1988): 214-24.

28. The Web site of the Council of Chief State School Officers provides access to state academic content standards: www.ccsso.org/projects/State_Education_Indicators/Key_State_Education_Policies/ 3160 . cfm. [Accessed 27 May 2009] 
rather than K-12 educators (who may not be as familiar with such systems). For example, the only way to know what is in the CLM's cartoon-rich historical periodicals and reprint books is to physically search them by hand. As much as the CLM staff would like to index the cartoons contained in them, such a labor-intensive project is not a practical option at this time. Given these access issues, it is unrealistic to expect busy teachers with limited financial resources, even those who live and work in central Ohio, to make full use of these materials.

The CLM has not been remiss in taking advantage of the opportunities digital technology and the growth of the Web have made available to special collections. An online database documents many thousands of its original cartoons, but using descriptive text only (no images). In addition, the library recently launched its Cartoon Image Database, ${ }^{29}$ which currently contains 422 editorial cartoons, along with other types of cartoons and comics, accompanied by basic metadata. Additional items are being scanned and added to it regularly.

However, even if all of the editorial cartoons could be made available in the image database, it is not clear that such a project would be the most appropriate way to serve educators. Large quantities of primary documents, unvetted and unaccompanied by interpretative and pedagogical materials, even when searchable, may not be the most effective method of promoting their use by teachers. In encouraging archivists to make education a more important part of their role, Osborne discusses the creation of "teaching packages" and argues that those that include explanatory materials and lesson plans are more helpful: "Whatever the reason, teachers apparently want help — and, of course, to provide suggestions for teaching activities does not compel teachers to use them." ${ }^{30}$

With the help of a private donor who was particularly interested in promoting the use of editorial cartoons in history classrooms, the CLM and the HTI joined forces to develop a program aimed at making it easier for social studies educators to make use of the CLM's extensive cartoon resources.

\section{Project Development and Execution}

The Opper Project team agreed it was imperative to collaborate with classroom teachers to select appropriate cartoons and to develop curricula that would be practical and useful. Practicing teachers would have the necessary theoretical background and hands-on experience developing and executing lesson plans. Cook explains, "the archivist can perform a major service to teachers and students by

29. The Ohio State University Cartoon Library and Museum, "Cartoon Image Database,” https:// cartoonimages.osu.edu/. [Accessed 27 May 2009]

30. Osborne, "Archives in the Classroom," 35. 
locating, collating, and publicizing relevant sources while not being called upon to attach pedagogical strategies to them. Providing these strategies is the role for senior teachers or other education professionals, ideally working ... in partnership with archivists and archival institutions." ${ }^{31}$ Accordingly, the team planned and implemented four-day workshops during the summers of 2006 and 2007 in which teachers were asked to develop lesson plans using editorial cartoons. Each year, six Ohio teachers from different school districts and grade levels were selected from a pool of applicants to participate. Teachers were paid an honorarium for their time and also received CEUs (Continuing Education Units).

In preparation for the workshops, graduate assistants were hired to mine the CLM's collection under supervision of the curators for cartoons on specific topics that were selected to coordinate with the Ohio Content Teaching Standards. (A list of the 24 topics is provided in Appendix A.) The Opper team then chose a subset of $12-15$ cartoons on each topic to be provided to the teachers in the workshop. In addition, introductory and supplementary materials were drafted, including an introduction to and history of editorial cartooning; worksheets on stereotypes, symbols, and caricatures; and a generic Editorial Cartoon Analysis Worksheet that could be used with any cartoon.

The first day of the workshop, the participating teachers served as a focus group, providing feedback about the usability of the introductory and supplementary materials. For example, teachers proposed that the order of the questions on the Editorial Cartoon Analysis Worksheet be changed so that students could begin with the questions asking for concrete answers before moving to the more difficult questions asking for analysis and interpretation. Other suggestions were purely practical and reflected the realities of teachers in schools with limited resources, such as the request that all worksheets be limited to one or two pages, because some schools only allowed teachers a limited number of photocopies each semester.

Next, the teachers were divided into two groups and each group was given six topics and the corresponding packets of cartoons. The second and third days were spent developing lesson plans for each topic using at least 4-6 of the preselected cartoons. On the last day, the groups presented their lesson plans to each other and to the Opper Project team for evaluation and critique. Each lesson plan included:

- A list of the Ohio Academic Content Standards in social studies addressed by the plan (including social studies skills and methods)

- Duration of lesson

- Learning objectives

31. Cook, "Connecting Archives and the Classroom," 108. 
- Summary

- Materials

- Pre-assessment questions or activities

- Instructional steps

- Post-assessment questions or activities

- Extension activities

The revised plans and their cartoons were posted on the Opper Project Web site, along with the revised introductory and supplementary materials, by a paid Web site developer. Graduate assistants and the Opper Project team members supplied the metadata and descriptions of each cartoon. One of the most time-consuming portions of this phase of the project involved seeking permission from the copyright holders of all cartoons published after 1922. Figures 1-3 provide an example of one of the lesson plans and accompanying materials. Figures 4 and 5 are examples of the editorial cartoons available to be downloaded for use with the lesson plan, along with the metadata and background information provided to teachers.

With the Web site in place, the Opper team moved to phase two of the project, which focused on raising awareness of the site and assessment. Although teachers were finding their way to the site through search engines and word of mouth, the team felt a more targeted effort was needed. A graduate assistant was hired to create and send announcements, advertisements, and other promotional material about the Opper Project to appropriate interest groups such as history and social studies teaching listservs and professional organizations. The marketing effort, which took place during October of 2008, produced immediate results. From January to September (excluding the summer months of June, July, and August when school is not in session), the site received an average of 904 unique visitors per month, or an average of 30 per day. In November and December of 2008, the Web site logged 2,852 and 2,108 absolute unique visitors respectively, for an average of 80 per day, a significant increase.

\section{Assessment: User Survey}

Once the awareness-raising effort was underway, an online survey was added to the site to give users an opportunity to provide the Opper Project team with feedback. A link to the survey was placed prominently on the Opper homepage, and visitors were asked to take five minutes to let the team know what they thought of the site. This survey method produces a self-selected or volunteer sample, which has the disadvantage of introducing bias to the results. However, it was the only option available given that the team could not identify or obtain a list of the population of visitors to the site that could be randomly sampled. Although the respondents could not be assumed to be a representative sample, every visitor to the site had 
an equal opportunity to complete the survey. Also, opportunities for qualitative responses were provided. In spite of the limitations of this assessment method, useful information was still obtained about who was using the Web site, how they were using it, and how satisfied they were with the pedagogical materials and primary sources provided. The survey was also intended to help the team identify any major problems with the site and possible improvements.

Survey data was collected between November 7, 2008, and March 6, 2009. A total of 67 surveys were completed. Of those, 55 were from teachers, 3 were from students, and 9 were from respondents who were neither. Appendix B lists the survey questions.

\section{Site Users}

The site is primarily aimed at high school-level educators, and, as expected, most of the survey participants were high school teachers. Of the respondents who identified themselves as teachers, which is the main constituency of interest in this study, 37 (69\%) were high school teachers, $9(17 \%)$ were from middle schools, 5 $(9 \%)$ from elementary schools, and $3(6 \%)$ at the college or university level..$^{32}$ The majority of the respondents had been teaching for more than 10 years $(34 ; 62 \%)$. Respondents came from 20 different states, with the highest number from Texas (11) and Ohio (10).

\section{Use of Lesson Plans and Cartoons}

The results indicate that the teachers who took the survey used the materials on the site in a variety of ways. Forty-six of the 55 teacher respondents $(84 \%)$ had viewed at least one lesson plan on the Web site. Forty-one (75\%) of them had either used one of the lesson plans in their classroom or intended to in the future. Just over half $(28,51 \%)$ of the teacher respondents used one or more cartoons from the Opper site separately from the lesson plan provided. Of those, 20 projected the image in their classroom, 19 printed it out for classroom group work or discussion, and 6 printed it for use in a homework assignment.

\section{Satisfaction}

The survey asked respondents which lesson plans they looked at and how satisfied they were with those plans on a scale of 1 to 5 , with "1" being "very unsatisfied" and " 5 " being "very satisfied." A total of 82 responses were received (respondents could choose to rate more than one lesson plan) with a mean satisfaction score of 4.17. Respondents were also given the opportunity to provide comments about

32. One respondent did not identify a grade level. 
the lesson plans. Only one score of "very unsatisfied" ("1") was given, and that respondent commented that many of the links were broken or the pages would not load. The project team was unable to replicate these problems. Several respondents expressed a desire for more cartoons or different topics:

"I would like to see a larger variety of topics and perhaps more cartoons to choose from for particular activities."

"Not enough cartoons."

"Interesting, although I hoped that it would be more useful to a non-Americanist." [American Imperialism]

Other respondents commented favorably on the overall Web site, the selection of cartoons, the quality of the images, and the usefulness of the magnifier feature, which allows users to enlarge specific sections of each cartoon.

"This is a great website, I use it all the time. Keep it up."

"The site is well thought out and has more than enough materials to keep a class engaged for an entire high school period."

"I love the wide variety of cartoons and the magnifier is wonderful!"

"The cartoons were great. The topics are very helpful to a US history teacher."

"I like the fact that it is very analytical-thinking based. The group discovery is good too." [Anti-Vietnam Conflict (War) Protest]

"I'm very impressed with the quality of images $\&$ the fact that you can download them."

Some responses indicated that teachers planned to modify the pedogogical strategies provided or incorporate the cartoons or other materials into their own lesson plans.

"Cartoons are awesome; I often take them and use them my own way that fits in with the time I am allotted for a particular topic."

"I teach AP so modification is needed."

"I think the lesson was excellent for the grades listed. Teaching a much lower grade, I will have to do a lot of 'tweaking' to make the lesson suitable. I am very pleased, though, with the lesson as a beginning point."

Of the ten respondents who had already used one of the Opper lesson plans, six were "very satisfied" with the way it worked in their classroom, giving it a " 5 " on a scale of 1 to 5 . Three teachers gave it a "4" and one a "3." The mean score was 4.5. 
When asked how likely they were to recommend this site to other educators on a scale of 1 to 5 , with 1 being "very unlikely" and 5 being "very likely," 38 of 55 respondents answered with a " 5 " and eight with a "4." The mean score was 4.45 out of 5 . The one respondent who was "very unlikely" to recommend the site (" 1 ") was a middle school teacher who did not look at any lesson plans or use any cartoons and reported that the site was very difficult to access from his or her school. A second respondent, also a middle school teacher, answered with a " 2 ." This is not entirely surprising, given that the Web site is specifically aimed at high school instructors.

It is reasonable to suppose that the teachers who voluntarily completed the online survey are those who found it the most valuable, thus favorably skewing the results. Therefore, it is useful to look at independent reviews of the site as well. In the journal Social Education published by the National Council for the Social Studies, C. Frederick Risinger and Ray Heitzmann wrote that the Opper Project site is "a good, teacher-friendly site" and "may be the best for history teachers looking to augment any historical event or era with political cartoons." ${ }^{33}$ The Scout Report, which reviews online resources for educators, librarians, and researchers, writes, "Much can be learned through close examination of editorial cartoons, and this fine online collection created by The Ohio State University Cartoon Research Library will be a welcome find for educators and students alike... The site is very user friendly, and visitors shouldn't miss the special worksheets that explore caricatures and common editorial symbols." ${ }^{34}$

\section{Discussion and Practical Suggestions}

Overall, the project team is pleased with the largely positive feedback and the evidence that teachers from around the country are making use of the site's materials. The Opper Project provides a model for collaborative ventures that can result in easily accessible educational resources designed to enhance secondary teaching and learning. Joining forces with university educators and with $\mathrm{K}-12$ teachers made it possible for the CLM to create a product that was far superior to what its staff could have produced on its own. The approach allowed the work to be spread out among the different partners and made it possible to keep expenses relatively low. ${ }^{35}$ The majority of the project's budget went toward hiring graduate students to help with research and marketing, providing honoraria for the workshop teachers, and

\footnotetext{
33. C. Frederick Risinger and Ray Heitzmann, "Using the Internet to Teach about Political Cartoons and Their Influence on U.S. Elections," Social Education 72.6 (Oct. 2008): 290.

34. The Scout Report 14.44 (Nov. 7, 2008). Available online at http://scout.cs.wisc.edu/Reports/ ScoutReport/2008/scout-081107-geninterest.php\#3.[Accessed 27 May 2009].

35. The budget for the project was $\$ 6,600$ in 2006 and $\$ 8,000$ in 2007 , both years in which the teachers' workshops were held. In 2008 , the budget was $\$ 8,686$, which included funds for marketing, evaluation, and redesign.
} 
paying a Web developer to create the Opper Project Web site. These expenses could vary depending on the nature of the topics and materials, the scope of the project, and the availability of in-house institutional resources. Using this model, another special collection at OSU, the Byrd Polar Research Center Archival Program, also partnered with the HTI to develop lesson plans using its unique primary source material. ${ }^{36}$ The scope of their project was smaller (they produced five lesson plans) and they did not need to hire graduate students to locate primary source material in the initial phase, so they were able to complete their project on a smaller budget. Of course, not all special collections are fortunate enough to have access to a group like OSU's HTI, but a partnership with a university's education department would be an alternative and could involve undergraduate and graduate education students in different ways (writing lesson plans, for example) for additional educational benefits.

Another factor that added to the cost of the Opper Project, but may not be an issue for other special collections, is copyright. Material published after 1922, and certain unpublished material, cannot be scanned or made available on the Web without permission of the rights holder. The American Library Association has developed an excellent tool, the "Digital Copyright Slider," that helps librarians navigate the complicated copyright laws. ${ }^{37}$ Special collections planning to use non-public domain materials should budget adequate staff time to managing copyright requests.

As both Gilliland-Swetland and Laver recommended, special attention should be paid to including experienced classroom teachers at all phases of the project. The Opper Project planning team did not initially include a teacher; and, although one was added after the workshops were completed, the team could have benefited from that person's expertise earlier on. During the feedback session at the end of the second teacher's workshop, it was suggested that one improvement would be to consult with the participants when choosing the topics for the lesson plans. Similarly, teachers commented that they wished they had known their topics ahead of time so that they could have done some preparation before the workshop. These requests could be accommodated as long as participants were selected far enough in advance.

Also, if at all possible, resources should be allocated to market the lesson plans after they are developed. The experience of this project indicates that concerted efforts are necessary in the beginning to spread the word about new programs to teachers. Don't assume that "if you build it, they will come."

36. Byrd Polar Research Center Archival Program and the History Teaching Institute, "Cold Cases: Lessons in Historical Skills and Methods," http:// hti.osu.edu/byrd/index.cfm. [Accessed 27 May 2009]. 37. Michael Brewer and ALA Office for Information Technology Policy, "Digital Copyright Slider," http:/ / librarycopyright.net/digitalslider/. [Accessed 27 May 2009] 
Future plans call for increasing the number of cartoons and topics and for establishing a national teacher's institute that would focus on training teachers to use editorial cartoons as primary documents. Also, because the workshops drew from a pool of Ohio teachers, the lesson plans are currently linked to the Ohio Academic Content Standards, although the standards of many states are similar. Future improvements include linking the plans to other state and national social studies standards.

\section{Conclusion}

Curators and archivists who preside over collections of primary source material increasingly seek to reach beyond their traditional audiences of scholars, faculty, and university-level students. Collaborating with educators to create lesson plans incorporating primary materials and making them available online is one way that special collections with limited time and resources and without dedicated outreach personnel can address this demand. Such partnerships take advantage of the separate skill sets of the two groups to benefit precollegiate users who may rarely, if ever, have the opportunity to visit the reading room of a special collection in person.

\section{O R N E B A I R R A R E B O O K S}

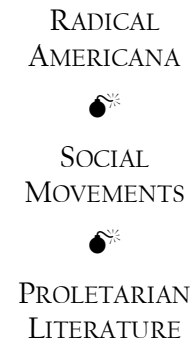

RADICAL
AMERICANA

LITERATURE

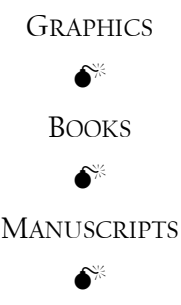

EPHEMERA 


\section{Figure 1.}

Opper Project Sample Lesson Plan

The Election of 1896-Gold or Silver?

Ohio Content Standard: Grade 11, History 4; Grade 12, History 3; Grade 12, Economics 7

Duration of Lesson: 2 class periods

\section{Learning Objectives:}

- Students will understand the issues behind the Election of 1896.

- Students will be able to describe the positions of William McKinley and William Jennings Bryan.

- Students will analyze editorial cartoons supporting McKinley's candidacy and evaluate the effectiveness of the cartoons.

- Students will create editorial cartoons supporting Bryan and explain their cartoons.

Summary: This lesson is designed to explore the Election of 1896 and how editorial cartoons were used to support the candidates. Students will analyze cartoons supporting McKinley's candidacy and create cartoons supporting the candidacy of Bryan. Students will determine the effectiveness in persuading the public's vote.

\section{Materials needed:}

\section{for Teacher:}

- Editorial cartoons 1-4 and accompanying overhead transparencies

- Election of 1896 Fact Sheet

- Overhead projector

\section{for Students:}

- Editorial cartoons 1-4

- Cartoon Analysis worksheet

- White paper for political cartoon drawing

- Drawing supplies

Pre-Assessment: Review with students the Election of 1896. A fact sheet is attached to this lesson if needed. A reading may also be made available to students or assigned from a textbook to provide some background information on this important election. 


\section{Instructional Steps:}

Day 1

1. Complete pre-assessment discussion.

2. Provide students with a copy of the four attached editorial cartoons and a Cartoon Analysis worksheet.

3. As a class, assign a number to each of the cartoons so that as students complete the Cartoon Analysis worksheet, they complete the cartoons in the same order.

4. Allow students time to analyze each cartoon and complete the Cartoon Analysis worksheet.

5. As a class, discuss the students' findings. Students will likely point out that these cartoons are all in support of McKinley. Ask students who they would vote for after analyzing these cartoons and why. Discuss the effectiveness of the cartoons.

\section{Day 2}

1. Review discussion from day 1.

2. Students prepare their own political cartoon in support of Bryan.

Post-Assessment: Students present their political cartoons, explaining their use of symbolism and the message of the cartoon.

\section{Extension Activities:}

- Students will write a summary of the political cartoon they created.

- Students will write summaries of the two candidates' political positions. 


\section{Figure 2}

\section{Election of 1896 Cartoon Analysis Worksheet}

1. Which candidate does the editorial cartoon support?

\section{Cartoon 1:}

\section{Cartoon 2:}

\section{Cartoon 3:}

\section{Cartoon 4:}

2. What audience would support the intended message of this cartoon and what audience would not support the message?

\section{Cartoon 1:}

\section{Cartoon 2:}

\section{Cartoon 3:}

\section{Cartoon 4:}

3. Describe how each of the two candidates is portrayed:

\section{Cartoon 1:}

\section{Cartoon 2:}

\section{Cartoon 3:}

\section{Cartoon 4:}

4. Is the message of this cartoon effective? Why or why not?

\section{Cartoon 1:}

\section{Cartoon 2:}

\section{Cartoon 3:}

\section{Cartoon 4:}




\section{Figure 3}

\section{Election of 1896}

\section{Fact Sheet}

- Many people considered the election of 1896 the most important election since Lincoln's election in 1860 because once again the nation was deeply divided.

- The American people were divided over the nation's money system, questioning whether U.S. currency should be backed with gold or silver.

- An economic depression that occurred in 1893 brought the currency issue to the forefront of political debate.

- At this time, the United States supported its money with gold. Those who supported the gold standard believed it would keep the value of the dollar high.

- Most who supported the gold standard were businessmen, bankers, and investors.

- Those who supported the silver standard believed the value of the dollar was too high and that a high dollar drove down the prices of agricultural products.

- Most who supported the silver standard were farmers, laborers, and small-business owners.

- The Republicans chose William McKinley as their presidential candidate and the Democrats nominated Congressman William Jennings Bryan.

- America's third party, The People's Party (the Populists) united with the Democrats to support Bryan because they too supported the silver standard.

- The two candidates campaigned very differently. Bryan traveled the country visiting 27 states spending only $\$ 650,000.00$ on his campaign. McKinley adopted the front porch campaign strategy inviting people to his home in Ohio to hear him speak. He spent around \$3,500,000.00

- McKinley won the election by less than 600,000 votes. 


\section{Figure 4}
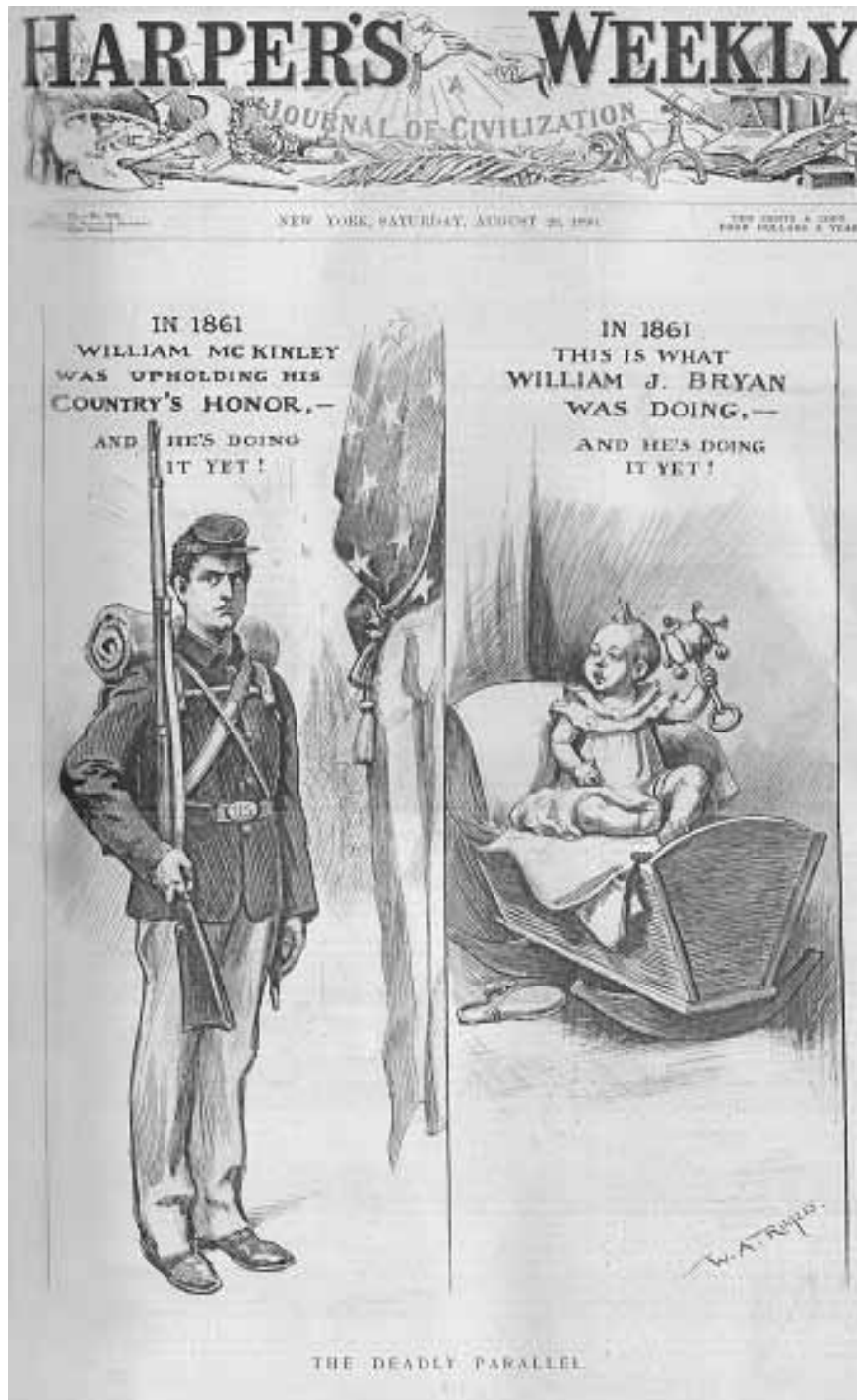

William Allen Rogers, “The Deadly Parallel,"Harper's Weekly via Review of Reviews Vol. 14, No. 4, October 1896.

Description: The 1896 election pitted Republican William McKinley vs. Democrat William Jennings Bryant. McKinley was a Civil War veteran and used that heritage to help him secure victory in 1896. Bryan was a political unknown and rather young, still in his thirties. Bryan's main platform was the free coinage of silver, outlined in one of the most famous speeches of the late 19th century, "Cross of Gold." His points were viewed by some as naïve and unsettling, the trademarks of rash youth. Bryan's campaign was conceived by opponents as being sectional and regional, pitting the rural, the poor, and the immigrant against the urban, native, and the middle-class/rich. 
Figure 5

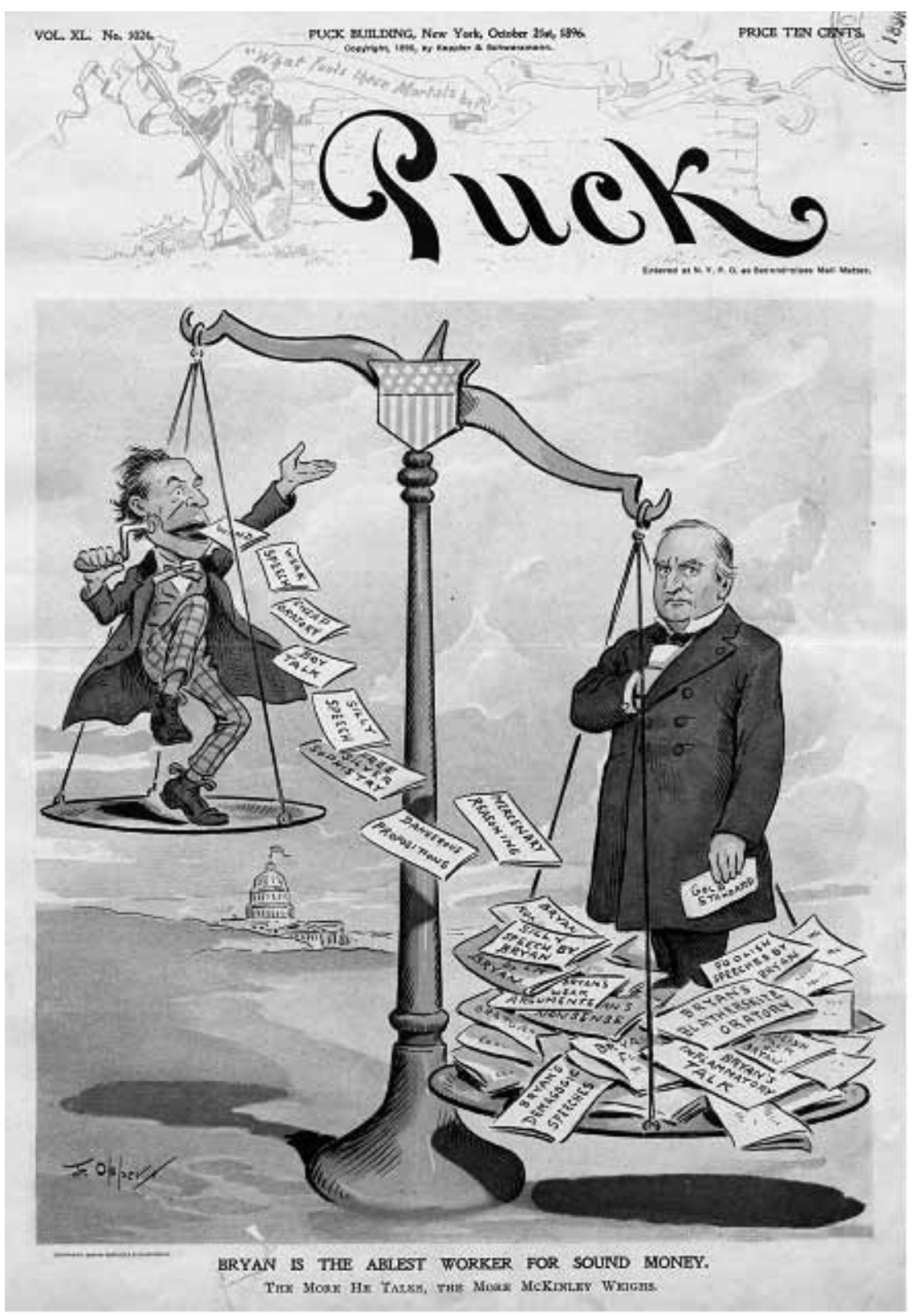

Frederick Burr Opper, "Bryan is the Ablest Worker for Sound Money," Puck Vol. 40, No. 1024, October 1896. 


\section{Appendix A \\ Opper Project Lesson Plans}

- American Imperialism

- Anti-Vietnam Conflict (War) Protest

- Business v. Labor and the Role of Government

- Cold War Conflict in Korea: 'The Powerful and Powerless United Nations'

- Cold War Conflict in Vietnam: 'The Vietnam-Era Presidency'

- Editorial Cartoons of WWII in Europe

- Energy Crisis

- Environmental Editorial Cartoons

- Immigration

- League of Nations

- Lincoln

- Nixon and Watergate

- Nuclear Weapons

- Progressive Reforms

- Prohibition

- Reconstruction

- The Civil Rights Movement

- The Election of 1896-Gold or Silver?

- The Election of 1912

- The Great Depression

- The Red Scare

- Treaty of Versailles

- Wilson's 14 Points

- Women's Suffrage 


\section{Appendix B}

1. Are you:

$\square$ A teacher

$\square$ A student

$\square$ Neither

2. What grade do you teach?

$\square$ Elementary school

$\square$ Middle school

$\square$ High school

$\square$ College or university

$\square$ Community college

3. How many years have you been teaching?

$\square \quad 1-2$

$\square \quad 3-6$

$\square \quad 7-10$

$\square$ More than 10 years

4. How would you characterize your school?

$\square$ Large city urban school

$\square$ Medium-sized city

$\square$ Rural

$\square$ Suburban

$\square$ Small town

$\square$ Home school

$\square$ College or university

$\square$ Community college

5. In what state do you live?

6. How easy was it to find what you needed on the Opper Web site? 1-5 (Not easy-Easy)

7. Did you look at a lesson plan?

$\square$ Yes

$\square$ No

[If Yes, respondent sent to \#8; if No, respondent sent to \#11]

8. Which lesson did you look at (choose the most recent)? List of all lesson plans provided 
9. How satisfied were you with the lesson you looked at? 1-5 (Very unsatisfied-Very satisfied)

10. Did you look at another lesson plan?

$\square$ Yes

$\square$ No

[If Yes, then repeat 8-10; if No, then respondent sent to \#11]

11. Did you use a cartoon or cartoons separately from the lesson plan provided?

$\square$ Yes

$\square$ No

[If Yes, respondent sent to \#12; if no, respondent sent to \#14]

12. From which topic area or areas did you use a cartoon or cartoons (check all that apply)?

List of all lesson plans provided

13. How did you use the cartoon(s)? Check all that apply.

$\square$ Printed out for use in classroom

$\square$ Printed out for use in homework

$\square$ Projected image in classroom

$\square$ Other, please specify

14. Is the Opper site difficult to access from your school?

$\square$ Yes

No

15. How did you locate this site? Check all that apply.

$\square$ Referred to it by another teacher

$\square$ Read about the site in professional publication

$\square$ Google or another search engine

$\square$ Link from American Association of Editorial Cartoonists Web site

$\square$ Link from Cartoon Research Library Web site

$\square$ Link from History Teaching Institute Web site

$\square$ Link from another Web site

$\square$ Received an e-mail announcement about it.

$\square$ Other, please specify

16. How likely are you to recommend this site to other educators? 1-5 (Very unlikely-Very likely) 